at PPCI in elderly patients such as SENIOR PAMI (Grines, 2005) and TRIANA (Bueno, 2009) the minimum age for inclusion was 70 yrs and 75 yrs respectively. With an ageing population in the western world, about $20 \%$ of patients admitted for suspected STEMI are $\geq 80$ yrs. We evaluated the outcome of PPCI in patients $\geq 80 \mathrm{yrs}$ who were admitted to our unit with STEMI.

Methods Our PPCI service was started in September 2009 and we analysed all the patients who were $\geq 80$ yrs presenting to the PPCI service between September 2009 and September 2010 (13 months). Prospectively entered data were obtained from our dedicated cardiac service database system (Philips CVIS). Mortality data were obtained from the summary care record (SCR) database. Follow-up data were obtained from patients' respective district general hospitals and general practitioners medical records.

Results Of the 998 patients who were admitted to our unit for primary PCI for suspected STEMI during the study period, 183 $(18.3 \%)$ were $\geq 80$ yrs of age. After excluding 51 patients $(27.9 \%)$ who did not undergo PPCI, we included 132 (70.1\%) patients for analysis. Of those who were included in the study $(n=132,63$ female), the mean age was $85 \pm 3.95$ yrs (range $80-99$ yrs, median $85 \mathrm{yrs})$. There were 20 diabetics $(15.2 \%)$ and $39(29.5 \%)$ had previous myocardial infarction. Ten patients $(7.6 \%)$ were in cardiogenic shock on arrival of which $9(90 \%)$ had an Intra aortic balloon pump (IABP). The infarct related vessel was the right coronary in $42.4 \%$ and left anterior descending in $37.1 \%$. Drug eluting stents were used in $40.2 \%$ of patients. In-hospital and 30-day mortality was $14.4 \%$ and $19.7 \%$ respectively. There was a significant difference in the mortality between patients age $<80 \mathrm{yrs}$ and those $\geq 80 \mathrm{yrs}$ (Abstract 45 figure 1). In patients $\geq 80 \mathrm{yrs}$, mortality and bleeding risk increased markedly with advancing age (Abstract 45 table 1).

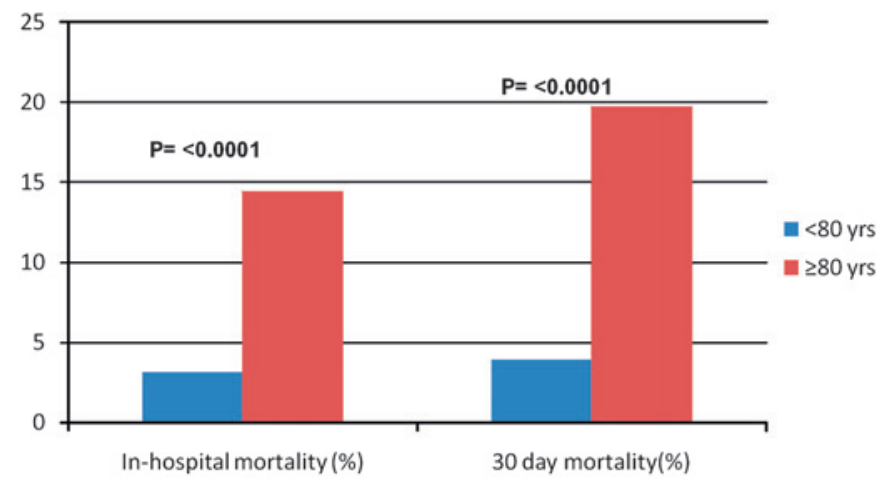

Abstract 45 Figure 1

Abstract 45 Table 1

\begin{tabular}{lccc}
\hline$\%$ & $\begin{array}{l}\mathbf{8 0 - 8 4} \text { yrs } \\
(\mathbf{N}=\mathbf{6 2})\end{array}$ & $\begin{array}{l}\mathbf{8 5 - 8 9} \text { yrs } \\
\text { (N=51) }\end{array}$ & $\begin{array}{l}\mathbf{2 9 0} \text { yrs } \\
\text { (N=19) }\end{array}$ \\
\hline Inhospital mortality & 9.7 & 15.7 & 26.3 \\
30-day mortality & 14.5 & 23.5 & 26.3 \\
30-day MI & 3.2 & 2.0 & 0 \\
30-day CVA & 1.6 & 0 & 0 \\
Major bleeding requiring blood transfusion & 1.6 & 3.9 & 10.5 \\
\hline
\end{tabular}

Conclusion This study clearly demonstrates a significant mortality difference between patients aged $<80$ yrs and those $\geq 80$ yrs treated with PPCI. Our 30-day mortality outcome in patients $\geq 80 \mathrm{yrs}$ $(19.7 \%)$ was similar to the subgroup analysis of the PPCI arm in similar SENIOR-PAMI patients (19\%). In the same analysis, the thrombolytic group had a lower $(16 \%)$ mortality. Further studies are required to determine whether PPCI should be routinely used in very elderly patients presenting with STEMI.

\section{PROGNOSTIC VALUE OF BASELINE RENAL FUNCTION ON LONG TERM OUTCOME IN PATIENTS UNDERGOING PRIMARY PERCUTANEOUS CORONARY INTERVENTION FOR ST-ELEVATION MYOCARDIAL INFARCTION}

doi:10.1136/heartjnl-2011-300198.46

O P Guttmann, K Rathod, B Rathod, E Wicks, S Gallagher, D A Jones, A Jain, C Knight, A Mathur, A Kapur, A Wragg. Barts and the London NHS Trust, The London Chest Hospital, London, UK

Background Renal impairment is associated with increased cardiovascular mortality following acute coronary syndromes (ACS), however there is limited data assessing this relationship in the context of primary PCI and whether it exists with other major adverse cardiovascular events.

Methods Clinical information was analysed from a prospective data base on 2310 STEMI patients who underwent primary PCI between January 2004 and May 2010 at a London centre. Information was entered at the time of procedure and outcome assessed by all-cause mortality information provided by the Office of National Statistics via the BCIS/CCAD national audit. Estimated glomerular filtration rate (eGFR) was calculated using the modified diet in renal disease equation and patients were divided into groups based on eGFR $(<40$, $40-50,50-60,>60 \mathrm{ml} / \mathrm{min} / 1.73 \mathrm{~m}^{2}$ ). 3-year composite of MACE (death, reinfarction, stroke and target vessel revascularisation) were compared between groups.

Results The average eGFR in all patients was $73.40 \pm 23.37$ (95\% CI 72.25 to 74.56$) \mathrm{ml} / \mathrm{min} / 1.73 \mathrm{~m}^{2}$. The prevalence of coexisting risk factors (hypertension, diabetes mellitus, hypercholesterolaemia), previous MI, previous CABG and cardiogenic shock were higher among patients with reduced eGFR. There was a progressive increase in MACE with declining eGFR ( $\mathrm{OR}=4.84,95 \%$ CI 2.94 to 7.96, for comparison between the highest and lowest eGFR groups). See Abstract 46 figure 1. After adjustment for baseline characteristics including age, diabetes and cardiogenic shock renal function based on the GFR at admission remained a strong independent predictor of outcome.

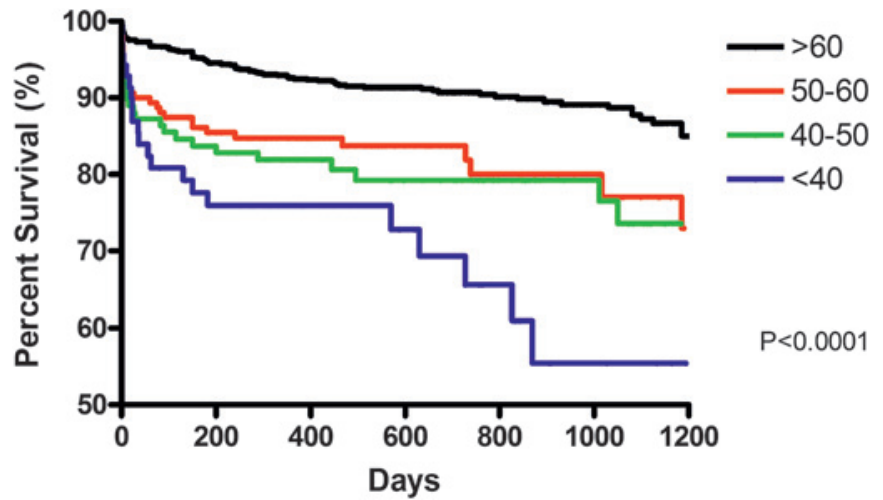

Abstract 46 Figure 1 All MACE after PCI for STEMI.

Conclusion Baseline renal dysfunction in patients undergoing primary PCI is associated with an increased risk for combined death, re-infarction and recurrent angina. This risk increases linearly with declining eGFR.

\section{CARDIOVASCULAR EVALUATION OF ENGLISH PREMIERSHIP RUGBY PLAYERS}

doi:10.1136/heartjnl-2011-300198.47

${ }^{1} \mathrm{~S}$ Ghani, ${ }^{1} \mathrm{H}$ Raju, ${ }^{1} \mathrm{~A}$ Zaidi, ${ }^{1} \mathrm{~N}$ Sheikh, ${ }^{1} \mathrm{~S}$ Gati, ${ }^{2} \mathrm{~J}$ Somauroo, ${ }^{3} \mathrm{~S}$ Kemp, ${ }^{1} \mathrm{~S}$ Sharma. ${ }^{1}$ St Georges University London, London, UK; ${ }^{2}$ Countess of Chester Hospital; ${ }^{3}$ Rugby Football Union (RFU)

Introduction Recent experience of pre-participation cardiovascular evaluation (PPCE) in Italian athletes demonstrates a significant 